\title{
Examining the Prospects for Developing a National Child Maltreatment Surveillance System in Ireland
}

\author{
Donna O'Leary ${ }^{1} \cdot$ Olive Lyons $^{2}(\mathbb{0}$
}

Accepted: 10 September 2021 / Published online: 10 October 2021

(c) The Author(s) 2021, corrected publication 2021

\begin{abstract}
The Irish Government pledged to reducing the prevalence of child maltreatment under the WHO Regional Committee for Europe plan on reducing child maltreatment. As a first step towards a rights-based and public health approach to maltreatment prevention, the WHO plan recommends making child maltreatment more visible across the region, with better surveillance through the use of national surveys that use standardized, validated instruments. We review the policy context, present current Irish data holdings, and outline some of the complexities reported in the literature concerning various surveillance methods in the context of the proposal to establish and maintain a surveillance system for child maltreatment in Ireland. Conclusions highlight the need for Ireland to adopting an approach to surveillance as soon as it is feasible. The paper outlines how such a programme is necessary to address the current absence of evidence on which prevention policies can be developed and to compliment the current child protection system. Drawing on a review of current methods in use internationally, we outline options for an Irish child maltreatment surveillance programme.
\end{abstract}

Keywords Surveillance · Child abuse · Child maltreatment - Children's rights · Data $\cdot$ Methodologies $\cdot$ Ireland

\section{Introduction}

Child maltreatment constitutes all forms of physical abuse, emotional ill-treatment, sexual abuse, deprivation, neglect, or exploitation of children resulting in actual or potential harm to a child's health, survival, development, or dignity in the context of a relationship of responsibility, trust, or power (CRC, 2011; WHO,

Donna O'Leary

oleary.donna@umail.ucc.ie

1 School of Applied Social Studies \& the School of Public Health, University College Cork, Cork, Ireland

2 Factor Inwentash Faculty of Social Work, University of Toronto, Toronto, Canada 
1999). Child maltreatment (CM) is a widespread phenomenon, constituting both a human rights concern and a major public health problem, with at least 55 million of the European Regions' 190 million children suffering some form of physical, sexual, emotional, or psychological maltreatment (Gilbert et al., 2009; Sethi et al., 2018). In developed countries where data is available, it is estimated that somewhere between half and $90 \%$ of all child abuse victims do not come to the attention of national child protection agencies (Fallon et al., 2010; Gilbert et al., 2009). In Ireland, the single national study of adults who experienced sexual abuse during childhood identified that only $8 \%$ had reported their experiences to authorities (McGee et al., 2002). CM is a public health concern, and statistics published by state agencies underrepresent the scale of the problem.

Surveillance systems using epidemiological methods are the cornerstone of effective services to prevent child maltreatment because they provide evidence on the distribution and determinants of $\mathrm{CM}$, which can be applied to inform the development and evaluation of preventive interventions (Fluke et al., 2020; Jud et al., 2016; Krug et al., 2002; Sethi et al., 2013). Different approaches yield different estimates and knowledge bases for potential interventions in CM, as is discussed below. In 2014, Ireland was one of the fifty-three member states of the WHO European Region which gave unanimous support to a resolution to reduce $\mathrm{CM}$ across the region and committed to better surveillance as a mechanism to achieve this (Sethi et al., 2013; WHO 2014, 2016, 2018). Ireland, through the office of the Chief Medical Officer in the Department of Health, is due to report on progress to the WHO in 2021 (WHO, 2014).

Risk factors for CM are best described through a framework based on the ecological model, which places maltreatment in the context of parent, child, family, neighborhood, and societal factors (Sethi et al., 2013). Accordingly, governments can use surveillance data to establish whether intervention is warranted at an individual, family, micro-level, or a broader macro-level (Sethi et al., 2013; Sidebotham, 2001; WHO, 1999). Jurisdictions with well-functioning surveillance systems can report trends in the prevalence of child maltreatment, provided the system is administered on a cyclical basis (Fluke et al., 2020; Meinck et al., 2016). This is beneficial for policymakers and administrators as it can support decisions for resource allocation and enable the planning, implementation, and evaluation of preventative policy and practice measures (Fallon et al., 2017; Jud et al., 2015, 2016; Trocmé et al., 2016a).

Ireland currently operates what is described as a passive surveillance system of child maltreatment and violence against children. Official statistics (discussed below) are limited to incidents referred to, and published by Tusla-Child and Family Agency, the national child protection and welfare service (Tusla), and crime statistics compiled by An Garda Síochána, the national police force (AGS), and published by the Central Statistics Office (CSO). This paper considers the prospects for a systematic surveillance programme for Ireland. The paper builds on the principle that all actions associated with reducing $\mathrm{CM}$ are underscored by the universal recognition of and respect for children's rights and human dignity. We review the policy context, present current Irish data holdings, and outline some of the complexities reported in the literature concerning various surveillance methods in the context of the proposal to establish and maintain a surveillance system for CM in Ireland. 


\section{The Policy Context}

\section{Maltreatment Prevention in a Public Health Framework}

It is long understood by the World Health Organisation (WHO) that public health $(\mathrm{PH})$ strategies aimed at preventing $\mathrm{CM}$ require multisectoral responses founded on robust data on the scale and scope of the problem (1999, 2002, 2013, 2014, 2018). As stated by Perry in his work on a PH perspective on violence (2009), $\mathrm{PH}$ provides a conceptual framework for understanding the causes of CM and developing strategies that will reduce the burden of suffering due to $\mathrm{CM}$ in the population. There is no agreement on a single approach to either the surveillance of or strategies aimed at the prevention of CM (see Gray \& Schubert, 2019; Parton, 2019; Reading et al., 2009). Some frameworks proposed include the rightsbased approaches (e.g., Reading et al., 2009), the socio-ecological framework (e.g., Krug et al., 2002), and more recently the structural perspective that aims to redress the underlying inequities contributing to children being harmed (see Axford \& Berry, 2018; Bywaters, et al., 2015; Wilkinson \& Pickett, 2009). These frameworks entail different conceptualizations of the problem and models of surveillance (the subject of this paper) and intervention to reduce and prevent $\mathrm{CM}$.

$\mathrm{PH}$ approaches help to address the limitations of current child protection and welfare (CPW) systems. Current Anglo-Saxon models of CPW, including the Irish model, are characterized as high-risk strategies as they focus on the identification and management of risks in reported cases, and secondary prevention through strategies aimed at reducing recurrence (Buckley \& Burns, 2015; Burns \& McGregor, 2019; Gilbert et al., 2012; Scott et al., 2016). These approaches are characterized by high and increasing demands for services, overrepresentation of disadvantaged groups and communities, and at times by poor outcomes associated with service fragmentation and high recurrence rates among those referred (Buckley \& O'Nolan, 2013; Scott et al., 2016). While CPW systems are extremely important, they do not address the causes and prevention of CM and can reinforce social inequalities because they ignore underlying structural factors, due to their focus on individual responsibility (Parton, 2019). Perry (2009) notes that there is a "prevention paradox" here, as high-risk approaches potentially offer benefits to specific individuals to whom they are offered but have limited impact on the population burden of suffering, whereas population-level approaches offer limited or non-benefit to the majority of individuals to whom they are offered but can exert significant impact on the burden of suffering in the population. Both are required to reduce the occurrence and consequences of $\mathrm{CM}$, but they entail theoretical tensions of collectivist versus individualist approaches (see Gray \& Schubert, 2019). Population-level prevention of CM requires attitudinal changes regarding the nature of risk to which policies respond and the question of who is responsible for addressing them, and require a commitment to prevention in the longer term (Klevens \& Alexander, 2019; Parton, 2019). 


\section{The Irish Framework}

Better Outcomes Brighter Futures (BOBF), the national policy framework for children and young people, is targeted at making Ireland "the best small country in the world for children to grow, where their rights are respected, protected and fulfilled" (DCYA, 2014). BOBF acknowledges advancements made in Ireland in developing evidence on children's lives through dedicated surveillance and survey programs that include data on children. Government has prioritized health surveillance in children, for example, the State of the Nation's Children Report (SONC), a biennial survey based on the National Set of Child Well-Being Indicators published in 2005 (see DCYA, 2016), and funded national longitudinal study of children and young people, Growing Up in Ireland, that commenced with an infant cohort in 2008 (see Nixon, 2019). Recent strategies have committed to improving data collection to ensure that children's lives are better understood (DCYA, 2014 p. 41; 2015); however, surveillance of childhood abuse is not specifically mentioned.

In Ireland, the Child Care Act (1991) provides the legislative basis for providing services to children not receiving adequate care and protection. Since 2011, the Irish CPW system has undergone comprehensive reforms to consolidate, reorient, and improve the delivery, management, and regulation of services. In 2014, Tusla was established as an independent state agency for Child Protection and Welfare and Domestic, Sexual and Gender-based Violence; heretofore, the Health Service Executive (HSE) provided these services (Burns \& McGregor, 2019). Tusla has the primary statutory duty to promote children's welfare, respond to child protection concerns, and protect children in situations where they do not receive adequate care and protection (Tusla, 2020a, b). A program for Prevention, Partnership, and Family Support (PPFS) established as part of the continuum of services developed by Tusla provides a range of programs on early intervention and preventative work (for a detailed overview of developments, see Burns \& McGregor, 2019). Children First, the National guidelines for Child Protection and Welfare, is the overarching mandate for statutory, professional, and community organizations working with children. Initially introduced in 1999 and updated in 2011, it was put on a statutory footing in 2017 resulting in the introduction of mandatory reporting of CPW concerns for professionals (DCYA, 1999, 2011, 2017; SI.No.470/2017 2017). AGS also has statutory responsibilities for the safety and welfare of children in emergency situations.

Since the 1990s, several reports have been published into the historical and current systematic abuse of children that occurred in family situations, in religious and state-run institutional settings, and in sporting organizations (e.g., Elliott, 2020; Gibbons et al., 2010; McGuinness, 1993; Ryan, 2009). These reports reveal the complex and challenging nature of the abuse concealed from authorities and services (Buckley \& O'Nolan, 2013) and situations where people with a sexual interest in children rose to power and prevented known child abusers from being removed from the organizations (Power, 2020). They were instrumental in radically reforming and developing the current child protection and welfare system (Buckley \& O'Nolan, 2013; Shore \& Powell, 2020).

The Irish system is characterized as evolving in two related, and competing, directions: child protection and child welfare (Buckley et al., 2011). As occurred in 
England in the early 1990s, Ireland broadened the parameters of concern for CPW policy, which represented a shift from a residual reactive system focused principally on non-accidental injury to one concerned with the "likely" risk of abuse or harm and the impairment to child welfare (McGregor, 2014; Parton, 2019). The recognition of typologies of abuse in addition to deficits in child welfare in "Children First" was reflected in the need for early intervention and preventive services and the investment in several specialist family support services, albeit they were targeted in specific geographic areas of particular disadvantage and need (Buckley \& Burns, 2015; DCYA, 1999).

Several commentators have acknowledged that the central ethos of Tusla's framework and the significant developments in the regulatory side of the state offer an opportunity to embrace a children's rights ethos and focus on strengths oriented and preventive services, but have questioned the capacity to achieve its goals because of economic constraints and structural factors including the focus on the confinement for responsibility for child protection to Tusla (Buckley \& Burns, 2015; Burns \& McGregor, 2019). As outlined above, the conception of prevention in the Irish system currently remains in the realm of secondary approaches that prioritize early intervention in populations already identified as being at risk and tertiary interventions through CPW, where the focus is on preventing recurrence of harm and abuse. While these high-risk approaches are necessary in identifying, assessing and intervening to prevent further harm and they are attractive to policymakers, they do little to stem the tide of new cases (Perry, 2009) for which a complimentary population approach is necessary (Reading et al., 2009). Furthermore, as is detailed below in relation to the Irish system, estimates of the prevalence of abuse and of victimization produced by the CPW systems are unreliable because they incorporate aspects of system-based definitions and assessment processes (Christ \& Schwab-Reese, 2020; Fallon et al., 2010).

\section{Statistics on Child Maltreatment in Ireland}

As mentioned, published statistics on the extent of child abuse in Ireland include those relating to children referred to Tusla, and statistics on recorded child victims of crime published by the CSO. Tusla publishes aggregated CPW performance and activity data relating to the number of referrals, and the categorization and responses to referrals per agency standards. Metrics include numbers of referrals processed within 24 hours, the number of Initial Assessments (investigations) completed within 40 days (21 days up to 2017), and the actions taken on completion of these Initial Assessments (see tusladata, 2020). Child-related metrics include the number of children listed on the Child Protection Notification System (CPNS), a register of children assessed by social workers to be at risk of significant harm, and the number of children in care. Up to 2009, CPW policy allowed referrals to include information on multiple children; since 2009 , the policy requires that each referral relates to a unique child (HSE, 2009).

Figure 1 presents national statistics for referrals and assessment for the years 2009 to 2019. The data shows a continuous rise in referrals to CPW from 35 per 1,000 


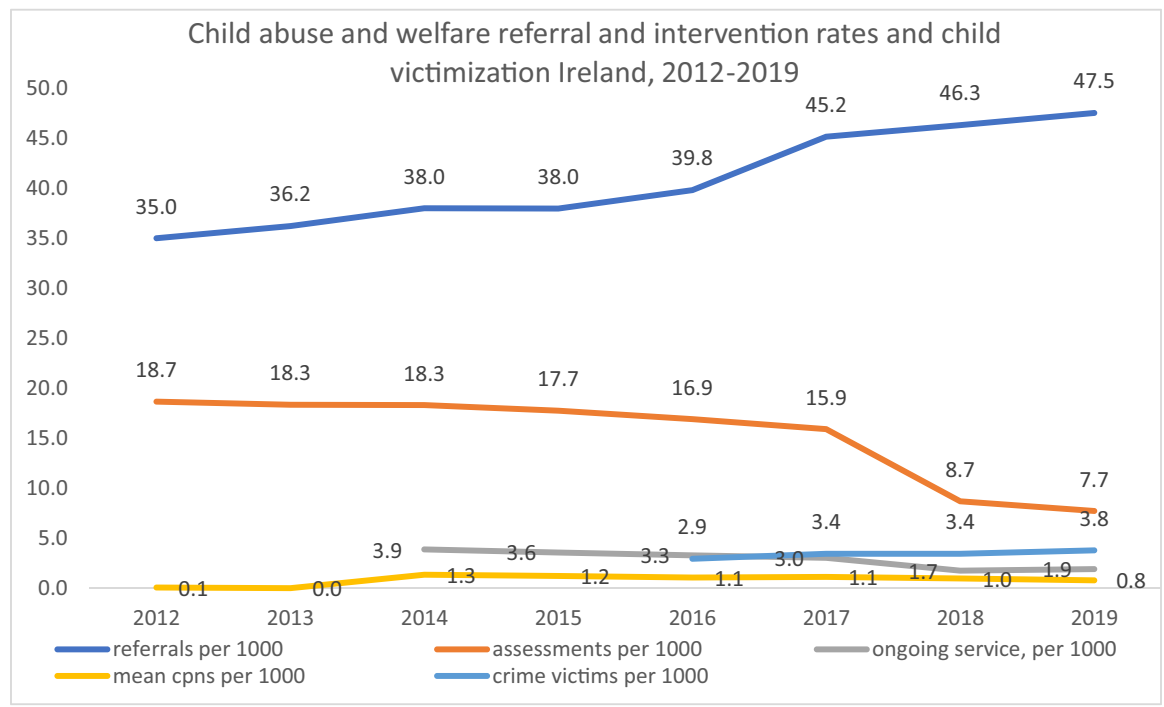

Fig. 1 Child abuse and welfare referral and intervention rates and child victimization, Ireland 2012-2019

children in 2012 to 47.5 per 1,000 in 2019. A sharp increase in referrals occurred from 39.8 per 1,000 in 2016 to 45.2 per 1,000 in 2018 , which is likely associated with the advent of mandatory reporting. Approximately half of all referrals proceed to Initial Assessment (IA), the Irish equivalent of an investigation, but the IA rate per 1,000 children has dropped in recent years. Most cases fall under the threshold for ongoing service provision and are closed under the heading - No Further Action (Tusla, 2015, 2014b; tusladata, 2020).

CSO data on child victimization form part of recorded crime statistics produced by AGS (the Irish police force). These are published under reservation by the CSO due to concerns about the completeness and accuracy of the underlying data in the system from which they are extracted. Statistics show an overall increase in the number of crime victims in the Irish population between 2016 and 2019. Rates for the entire population (not shown here) rose from 3.7 victims per 1,000 people in 2016 to 4.9 per thousand in 2019. Children under 18 years of age comprise just over $19 \%$ of these recorded crime victims. The data reveal a similar pattern, showing an increase from 2.9 victims per 1,000 children in 2016 to 3.8 in 2019. Together, these data suggest that the perception of child victimization may indeed be increasing. However, trends in increased rates in referrals both to CPW and AGS reflect changes in policies that made reporting to AGS easier and, in the case of CPW in 2018, mandatory for many professionals.

Other features of CPW data raise questions about its limitations in reflecting population-level concerns about child abuse and victimization. As in other jurisdictions, there is clear evidence at the population level of a social gradient in referrals to child protection services (O'Leary et al., 2015), indicating that children from disadvantaged areas are disproportionately represented (Bywaters et al., 2015; Scott et al., 2016). Corresponding data for rates of assessment and intervention have been reducing from 2012 
to 2019 (see Fig. 1) and relatively few cases receive intervention beyond assessment (Buckley \& Burns, 2015; see also, Thorpe, 1997; see Fig. 1), a pattern familiar across many contemporary CPW services and may incorporate features of assessment processes and competition for scarce resources (DHSS, 2020; see Lonne et al., 2020). The aggregated statistics relate only to referrals and assessments completed within timeframes set for performance monitoring within the system and thus do not include all referrals processed. The system does not produce evidence of characteristics of children and family's referred. As in the UK, the current risk assessment focuses on the likelihood of future significant harm (Tusla 2014a), although a policy on substantiation of abuse having occurred is due for implementation in the coming year (Tusla, 2020a, b) (see below). Currently, coverage of children specifically victimized by domestic violence is not captured in the Tusla data but policy changes to revise this are under consideration (Furey \& Canavan, 2019).

As this brief review shows, Irish statistics on child abuse and child victimization cannot serve as a proxy for evidence of the incidence or prevalence of child abuse at the population level nor that which comes to the attention of the state's agencies. Nor can it be used to provide evidence of how to develop primary preventive services. Focusing on data reported to CPW and AGS could result in zero to limited coverage on specific subgroups who have never interacted or have had limited interaction with specific administrative systems. Surveillance programs aim to cast a net wider than CPW agencies to improve the opportunity to represent experiences of subgroups otherwise not captured. In the next section, we review the alternatives available for such surveillance programs.

\section{Current Approaches and Methodologies for Child Maltreatment Surveillance}

Surveillance involves the ongoing systematic collection, analysis, and interpretation of data on child abuse incidence and prevalence. Methodologies differ across potential data sources and approaches involving continuous data collection (e.g., CANMDS, 2021) and those using cyclical, cross-sectional methods (e.g., Sedlak et al., 2010; Trocme et al., 2001, 2010; van Berkel et al., 2020). A brief overview of the three main approaches currently applied in CM surveillance: population-based surveys, sentinel-report surveys, and agency surveys is outlined. First, we examine the potential for using administrative data as a source of prevalence data on CM.

\section{Administrative Data}

Administrative data refer to information collected by public sector agencies for "registration, transaction and record keeping" when delivering a service (Woollard, 2014, p. 49). While the original intention may be unrelated to surveillance, administrative datasets from CPW agencies can prove to be a valuable source of knowledge of reported cases of CM (Fallon et al., 2017). These datasets can offer up-to-date information relating to the nature of referrals, source of reports, evidence 
of substantiated abuse, demographic characteristics of children and families, out of home placements, and service responses received (Fallon et al., 2017; Trocmé et al., 2016a, 2016b).

The National Child Abuse and Neglect Data System (NCANDS) in the USA is an example of an administrative dataset. It is unique across all countries as it utilizes country-wide administrative child welfare data annually from all 50 states, the District of Columbia, and Puerto Rico (AlEissa et al., 2009; USDHHS, 2021). Originally based on aggregated data on key indicators of child protective services, NCANDS now contains case-level data on all children subjected to a child protection service (CPS) response in addition to agency file and a summary data component (Fallon et al., 2010; USDHHS, 2021). The case-level data provide yearly information relating to screened-in referrals, including the characteristics and risk factors of the child and family, the nature of the maltreatment, the determination of CPS response, and any follow-up actions (Jud et al., 2015; Sedlak et al., 2010). However, caution is warranted when comparing findings as definitional variance exists between states (USDHHS, 2021).

Several jurisdictions have considerably enhanced the value of statistics routinely published by states' agencies in recent years by including child-level metrics. For example, Aotearoa/New Zealand and Australia publish child-level information on the characteristics of and responses to children involved with child protection and youth justice (AIHW, 2021; Oranga Tamariki, 2021). The four countries in the UK independently collect and report child maltreatment data relating to children who become subject to a "child in need" categorization after referral to child protection services; the data are completed on an annual basis through an administrative dataset (AlEissa et al., 2009; Dept of Education, 2020). In England and Wales, child-level child abuse and crime victimization data from the government and the voluntary sector has been published for many years (NSPCC, 2013-2019). Yet, despite having this enhanced data, governments in England and Wales are currently undertaking a feasibility study to ascertain if conducting a new survey to effectively measure the current scale and nature of CM is needed (ONS, 2021).

\section{Strengths}

A significant strength of CM administrative data is that governments can use it to ascertain the burden of abuse and need reported to state agencies. In turn, these datasets can provide information that is mutually beneficial to clients, researchers, and agency staff, and have the potential to influence policymakers as they can assess the functioning of a child protection system (Drake \& Jonson-Reid, 1999; Hurren et al., 2017; Jud et al., 2016, Jud, 2018). In CPW agencies, the extraction of information from administrative data places no additional labor on child welfare workers and can be a cost-effective means of retrieving incidence data (Jud et al, 2015). In some jurisdictions, administrative data can be linked to other related data such as justice or welfare data, creating large samples that allow for child maltreatment to be examined at a population level (Brownell \& Jutte, 2013; Drake \& Jonson-Reid, 1999; Trocmé et al., 2019; Vaithianathan et al., 2017). In addition, these datasets 
allow for longitudinal data analysis of contact with multiple systems over time and enable researchers to study distinct subgroups throughout the life course (Hurren et al., 2017).

\section{Weaknesses}

Administrative data pose limitations when estimating prevalence, as only children referred to CPW services in a jurisdiction are included (Brownell \& Jutte, 2013; Fallon et al., 2010). Administrative systems vary in the data and quality of data they collect considering that they were not initially designed for research purposes, and the variables of interest are not always present (Brownell \& Jutte, 2013; Drake \& Jonson-Reid, 1999; Scott \& Faulkner, 2019). Consequently, comparisons between regions using administrative data are limited due to definitional variability, legal constructs and service provision (Buckley \& Whelan, 2018; Furey \& Canavan, 2019). While initially viewed as a cost-effective method of retrieving incidence data, there are greater costs incurred when linking and analyzing the data: this requires specialized analytic support, personnel, and financial resources to transform administrative datasets to use for research purposes (Fallon et al., 2017; Hurren et al., 2017; Trocmé et al., 2019).

\section{Sentinel Surveys}

Sentinel methods refer to survey data gathered from professionals in the community who routinely work with children or families and are likely to be aware of child maltreatment concerns. These "sentinels" can include personnel in CPW agencies, hospitals, social services, childcare, education, police departments, and the judiciary who have contact with children and are likely to be aware of CM concerns (Fluke et al., 2020; Jud et al., 2016). The aim is to establish prevalence estimates of abuse that are recognized within communities (Fluke et al., 2020).

There are three established nationally representative surveys that produce estimates on the nature and extent of reported CM using this method: these are the National Incidence Study (NIS) in the USA, the Canadian Incidence Study (CIS), and the Netherlands Prevalence Study of Child Maltreatment (NPM) (Euser et al., 2013; Sedlak et al., 2010; Trocmé et al., 2010). The CIS focuses solely on professionals working in child protection agencies. Within the European Region, the Coordinated Response to Child Abuse and Neglect (CAN) via a Minimum Data Set (MDS) is an incident-based surveillance system currently being piloted in seven countries (CAN-MDS, 2021). CAN-MDS adopts an intersectoral approach for data collection, which uses a standard methodology across countries intending to be available for implementation in all 27 member states (Ntinapogias et al., 2015). 


\section{Strengths}

CPW agency professional surveys are useful as an approximation of reported cases of $\mathrm{CM}$ and provide trend data if administered on a cyclical basis; importantly, for governments, this trend information is provided at a lower cost than longitudinal data collection (Fallon et al., 2010; Meinck et al., 2016). Agency surveys in some jurisdictions have raised awareness of $\mathrm{CM}$ at a broader level. For example, CIS has facilitated knowledge development and transfer from agencies to government, assisted in developing differential response models, and assisted CPW agencies in using this data to establish service responses (Fallon et al., 2017; Tonmyr \& Martin, 2014). When reported in conjunction with other methods, such as administrative data and CPW agency surveys, sentinels provide a closer approximation of actual child maltreatment in the population (Meinck et al., 2016). Sentinel records are used more broadly as a tool for policymakers to ensure equitable resource allocation and service response to referrals and as a means of evaluating the efficacy of policies for child maltreatment prevention (Jud et al., 2016; Meinck et al., 2016; Trocmé et al., 2016a, 2016b).

\section{Weaknesses}

Agency surveys can potentially create an additional work burden for staff in terms of training and form completion, resulting in a barrier to participation as workers are already heavily taxed in terms of time and cognitive load (Christ \& SchwabReese, 2020; Jud et al., 2015; Trocmé et al., 2016a). In addition, each cycle of data collection involves new children (for example, every 5 years), thus "limiting the conclusions that can be drawn longitudinally (causality)" (Scott \& Faulkner, 2019, p. 262). The time between cycles and the costs incurred in data collection for surveys make it difficult to ascertain the actual impact this methodology has on changes in policy and practice (Leeb \& Fluke, 2015). Sentinel methods are prone to similar limitations as CPW surveys, in that only children who are in contact with agencies in the community will be included.

\section{Population-Based Surveys}

Population-based surveys, also known as self-report or informant surveys, are administered to representative sample of population of interest (Meinck et al., 2016). In studies relating to $\mathrm{CM}$, data can be collected face-to-face or through telephone or online interviews from the sample of interest, such as adolescents or adults victimized in childhood (Fluke et al., 2020; Jud et al., 2016). Representative surveys with young people can be carried out through the school system (Meinck et al., 2016).

A number of validated survey methods exist for gathering information from children and adults. ISPCAN, in collaboration with UNICEF, the UN Secretary General's Study on Violence against Children, the Office of the High Commissioner of Human Rights, and the WHO, developed a suite of International Child Abuse 
Screening (ICAST) tools and guidelines for their use. A primary aim of these tools is to enable the systematic collection of comparable data on the extent and depth of child abuse (Runyan et al., 2015; ICAST). The tools, which include a version for parents (ICAST-P), young adults (ICAST-P), and children over 11 (ICAST-P), have been internationally reviewed and tested and translated into more than 20 languages for use worldwide (e.g., Nikolaidis et al., 2018). Additionally, the Adverse Childhood Experiences (ACEs) tool gathers self-report information (Anda et al., 2006). The WHO noted that current child health surveillance approaches such as the Health Behaviour in School-aged Children (HBSC) offer potential mechanisms to support $\mathrm{CM}$ and child mental health well-being data collection programmes at the population level (Meinck et al., 2016).

The SAVI Report: Sexual Abuse and Violence in Ireland, published in 2002, is an example of a self-report study of the prevalence of various forms of sexual violence among Irish women and men across the lifespan from childhood through to adulthood (McGee et al., 2002). Based on a representative population-based survey involving over 3,000 Irish participants, SAVI revealed that one in five women and one in six men experienced contact abuse, and one in ten women and one in fourteen men experienced non-contact sexual abuse, during childhood (McGee et al., 2002).

\section{Strengths}

Population surveillance is beneficial as it yields prevalence rates for CM for entire populations from the representative sample (Meinck et al., 2016; Sethi et al., 2013). Indeed, these surveys are most useful when measuring and comparing exposures across countries (Meinck et al., 2016; Runyan et al., 2015). Representative population-based surveys are a cost-efficient means of gathering surveillance data in lowmiddle income countries (Jud et al., 2015; Leeb \& Fluke, 2015). When trying to achieve "proper surveillance" of child maltreatment in a society, Christ and SchwabReese (2020) argue that this is best realized through random population-based surveys as this methodology illustrates what is unknown or unreported to child protection systems.

\section{Weakness}

Certain limitations exist when collecting data through adult self-report, as memories may be biased or flawed and offer rates of prevalence that are historic (Jud et al., 2016). While adolescent self-report is possibly more reliable as the information is from the recent past, there are ethical implications to consider when interviewing those under eighteen (see below) which may limit contact with certain subgroups of children (Jud et al., 2016). Finally, on a policy level, population-based surveys alone do not afford policymakers insights into child maltreatment which transfer to concrete policy changes (Jud et al., 2016). 


\section{Summary}

As outlined here, there are strengths and weaknesses associated with each approach arising from the different ontologies and methodologies and the type of knowledge they produce. Gray and Schubert (2019) illustrate that two ideologies exist, one which advocates for a public health approach that recognizes $\mathrm{CM}$ as a risk for entire populations and one which endorses the view that efforts should focus on high-risk populations, in this case poor and economically deprived communities and individuals, leading to divergent solutions. Surveillance systems that collect data from multiple sources are considered most helpful in developing comprehensive responses to prevent child abuse (Gilbert et al., 2012; Leeb \& Fluke, 2015). Two systems in particular that serve as models are the National Incidence Study of Child Abuse and Neglect (NIS) in the USA and the Netherlands Prevalence study of Maltreatment of children and youth (Euser et al., 2013; Sedlak et al., 2010).

\section{Key Considerations}

\section{Oversight and Financing}

In Ireland, as in many other countriesthe responsibility for child maltreatment prevention lies with the CPW system, the police, and the judiciary (Butchart \& Mikton, 2014). The WHO recommends that government-led, national child maltreatment surveillance systems incorporate all sectors, have a lead agency with a national coordinating role, and be developed in parallel, not in competition with the existing child protection system $(2014,2015$; Meinck et al., 2016). In Ireland, the commitment to undertake surveillance was given through the office of the Chief Medical Officer under the Department of Health providing the potential for a broader scope than the current CPW framework .

WHO advises that surveillance systems' development, implementation, and sustainability rely on continuous funding and partnership with those involved in data collection (WHO, 2014; Jud et al., 2015). Partnerships between universities and government serve as beneficial collaborations, as universities have the necessary technical expertise to develop good-quality monitoring, analysis, documentation, interpretation, reporting, and dissemination (Fallon et al., 2010; Jud et al., 2015; Meinck et al., 2016). Within the EU, as mentioned above, funding is available to support national efforts through several programmes including the Rights, Equality and Citizenship Programme (EC, 2018). In addition, there are opportunities for Ireland under the current EU-sponsored surveillance programme CAN-MDS.

\section{Definitions and Measures}

For the most part, there is theoretical consensus in the academic fields on definitions of specific child abuse categories (Christ \& Schwab-Reese, 2020). However, a lack of agreement on how these constructs are operationalized within legal and CPW 
contexts makes related data susceptible to variation, with $\mathrm{CM}$ definitions and subcategories differing and overlapping depending on the professional context (Christ \& Schwab-Reese, 2020; Scott \& Faulkner, 2019). When applying epidemiologic surveillance for child maltreatment, the lack of universal definitions for key terms presents challenges, with variation across jurisdictions, cultures, systems, and agencies (Christ \& Schwab-Reese, 2020; Scott \& Faulkner, 2019). Furthermore, details of how each abusive event will be measured, either at a child or family level, and whether this will be a cross-sectional or ongoing measurement need to be considered (Scott \& Faulkner, 2019). Parton (2006) stressed that the subjective meaning that children give to events is often at variance with what adults might expect. In developing valid definitions, consideration needs to be given to the meaning imputed to experiences by young people concerned.

In Ireland, definitional inadequacy has affected data collection within the current child protection system, with variation evident between geographical areas a cause for concern (Buckley \& Burns, 2015; Burns \& McCarthy, 2012). As far back as 1987 , efforts were made to institute standard definitions for use in child welfare (Buckley \& Burns, 2015). A decade later, attempts were initiated through the national policy, Children First, to imbue a more holistic approach to child protection and welfare; this offered uniform definitions of child abuse and neglect for all sectors working with children (DCH, 1999). Thus, in theory, a common definitional framework exists in Ireland however, evidence suggests that insufficient definitional clarity exists at the CPW level (Burns \& McCarthy, 2012; Horwath, 2005). A recent study of the police service involvement with child protection services in Ireland found inconsistencies surrounding the notion of risk to children that negatively impacted their statutory duty to collaborate to protect children (Shannon, 2017).

One of the noted limiting issues with definitions of CM within CPW systems is that maltreatment can be confounded with its causes or consequences for evidentiary purposes in practice (Christ \& Schwab-Reese, 2020). Christ and Schwab-Reese (2020) recommend that research on CM necessitates a recognition of child maltreatment that is broad and unconstrained by cultural norms of individualized responsibility and by institutional practices. This certainly is a current concern in Ireland, where mandatory reporting came into effect in 2017, and a policy for substantiating child abuse is forthcoming. That policy, based on the interpretation of the duty on Tusla by the Irish courts, requires Tusla to investigate complaints of abuse and mitigate any risks that are identified in respect of a reported child and any child who has contact with an alleged abuser, and to disclose the allegation to third parties. As a result, discussions about abuse are increasingly framed in legalistic terms in public discourse (O'Mahony, 2020). Any surveillance system would need to address the possibility that CM would be formulated in such evidentiary terms and would need to be devised in a way to take account of any possibility of revictimization that survey methodology might induce. Whichever surveillance method is employed, the system's design and the protocols and training tools for those involved must clarify the distinction between definitions for purposes of surveillance and for reporting to Tusla for CPW investigations. 


\section{Technical Issues: Tools and Training}

Common technical issues that exist at a universal level regardless of the surveillance program include time, implementation of the system, recruitment, and collaboration between government and agencies (Jud et al., 2015).

Idiosyncratic features of each potential measurement tool need an appraisal before adoption. For instance, agency surveys, which are judged to be of a higher methodological standard than population-based surveys, might pose a challenge by potentially creating an additional work burden for staff required to collect the data (Christ \& Schwab-Reese, 2020; Jud et al., 2015; Trocmé et al., 2016b). However, based on the implementation of surveillance systems in other countries, recommendations and resources are available to circumvent potential technical challenges. For example, several experts recommend that research and technical supports should be offered to workers who participate in surveillance studies (ChildONEurope Secretariat, 2009; Jud et al., 2015). Based on the implementation of a Swiss surveillance system that incorporated population and agency surveys, Jud and colleagues (2018) advise sending clear, non-academic letters to agencies to invite their participation, and to suggest engaging frontline staff and administrators by seeking their input into the creation of relevant study variables through a Delphi-type approach. Lastly, they echo the need to provide research support and a helpline for frontline staff throughout the study (Jud et al., 2018).

WHO has published a toolkit on mapping legal, health, and social services' responses to child maltreatment that serves as a resource for researchers and decision-makers who use sentinel surveys and provides further guidance to what is outlined briefly here (Jud et al., 2015). The European CAN-MDS toolkit (Ntinapogias et al., 2015) also includes an operator's manual, data-collection proto$\mathrm{col}$, training modules for professionals, and methodology to define relevant sectors' eligibility criteria. The toolkit is currently adapted for seven countries.

\section{Ethical Considerations}

In the appraisal of a potential surveillance system for Ireland, attention needs to be given to a number of ethical issues that arise. The key ethical considerations for a surveillance system, whichever mechanism is adopted, are the common good, equity, justice, respect for individuals, and good governance (WHO, 2017). Some ethical considerations will differ depending on the mechanism used for data collection (UNICEF, 2018). Researchers in the field have suggested that the predominance of research on CM epidemiology has focused on population surveys with adult respondents with less attention paid to analyzing reported incidents of alleged child maltreatment and corresponding agency responses (Jud et al., 2016, p.10). The latter can be of greater benefit to policymakers because they provide information about the functioning of a child protection system (Jud et al., 2016; Jud 2018; Meinck et al., 2016). 
Researchers are advised to include constructs that embrace cultural contexts through use of language and "belief systems" (Fluke et al., 2020) when considering definitions of child maltreatment (Ntinapogias et al., 2015). This is especially relevant to enable researchers to be sensitive to cultural issues outside of their own expertise (Graham et al., 2013). Parton suggests that a major problem with some current attempts to collate and share a wide range of information about concerns that professional have about children is that they grossly underestimate the background and contexts for those concerns and, crucially, the meanings imputed to them by the key actors, particularly the children and young people themselves (2006, p180). As a consequence, he suggests that while children are placed at the center of services, there is a great danger that services will not be child-centered (2016, p185). In order to be useful and reflective of children's rights, Parton (2006) suggests that in the first place, children and young people need to be involved in identifying and giving meaning to the nature of their concerns and secondly, that they need to be central in deciding what they want done about them.

All surveillance methods must adhere to stringent ethical protocols regarding privacy and confidentiality throughout the research process, from the physical spaces for data collection to maintenance and storage and dissemination of data (Meinck et al., 2016; Ntinapogias et al., 2015; UNICEF, 2018). Methods adopted will need to comply with Irish legislation and European regulations for data privacy (Data Protection Commission, 2019; EP and CEU, 2016). A protocol requiring mandatory reporting is necessary in the event of a child disclosing abuse or the researcher having reasonable grounds to suspect same; it is recommended that a child protection reporting policy be agreed in advance and embedded into the ethical framework of a project (Graham et al., 2013; UNICEF, 2020). Whatever surveillance system is adopted, protocols must be in place to ensure those involved have valid professional licenses and are subject to a professional code of ethics (Ntinapogias et al., 2015).

In population-based surveys, the main ethical issues include informed consent and informed assent of child and parent/guardian, the avoidance of harm, beneficence, privacy and confidentiality, and compensation for research participants (CP MERG, 2012; Fluke et al., 2020). Including children in data collection requires additional precautions. Children as autonomous individuals are in a position to provide consent; but it is essential for the integrity of data collection that informed voluntary consent is obtained from both child and caregiver with a full understanding for the risks and benefits (Mathews et al., 2020; UNICEF, 2018, 2020). In situations where children are not legally able to consent, it is essential to obtain their assent in an age-appropriate manner to ensure they agree with participation (UNICEF, 2018, 2020). Issues surrounding consent are particularly salient in the context of child maltreatment as the child might be suffering abuse from the parent/caregiver and thus consent from this person might not be appropriate; a passive consent from caregivers might be a way to circumvent this dilemma (CP MERG, 2012). Crucially, researchers must endeavor to protect children and minimize harm and possible retraumatization at all stages of the process, from the beginning and through gathering, analyzing, and ultimately disseminating all data (Graham et al., 2013; UNICEF, 2018). 
Ethical considerations such as consent and assent are necessary but may impede and skew surveillance data collection as only children whose parents consent are surveyed (Scott \& Faulkner, 2019). Self-report methodologies need to consider the potential impacts of disclosing abuse on adult and child victims and need to put in place support systems to ensure participants' safety and security (CP MERG, 2012).

\section{Concluding Comments}

Protection from child maltreatment is a human rights issue. Our purpose here is not to suggest how interventions might be developed, rather it is to highlight the necessity of surveillance in pursuing this endeavor. A commitment to develop evidence on the prevalence of CM needs to be matched with a commitment to enhance or develop interventions that will specifically respond to identified needs. Developing a surveillance programme recognizes that data itself is a mechanism for change (UNICEF, 2018). This value is recognised in the reporting requirements under the UN Sustainable Development Goals (UN 2015). It is only through understanding the problem of child maltreatment that effective policies can be developed, and sustainable actions can be taken to systematically reduce and prevent it (UN 2015). As such, there is a moral imperative to implement a sustainable surveillance programme (see Table 1). This requires political foresight and long-term commitment to investing in twin approaches to reducing and responding to CM as outlined above. The Irish Government's undertaking to commence a child abuse surveillance system (WHO, 2014) offers the exciting potential to extend and enhance recent infrastructural investments within the Irish child protection and abuse prevention systems.

As described, each surveillance method comes with its own merits and drawbacks. Overall, the best surveillance is one which incorporates triangulation of multiple data

Table 1 What makes a good surveillance system?

\begin{tabular}{|c|c|}
\hline Simplicity & $\begin{array}{l}\text { The system should produce the data needed in the most simple and straightforward way } \\
\text { possible }\end{array}$ \\
\hline Flexibility & $\begin{array}{l}\text { The system should be able to adapt at minimal cost to changes in the operating condi- } \\
\text { tions and the data required }\end{array}$ \\
\hline Acceptability & $\begin{array}{l}\text { Those people who are expected to provide information, through interviews and in other } \\
\text { ways, should be willing to participate and should be involved in the system design } \\
\text { where possible }\end{array}$ \\
\hline Reliability & $\begin{array}{l}\text { A reliable system is one that detects an overwhelming proportion of the actual cases in } \\
\text { the target population and excludes most non-cases - that is, the system should have } \\
\text { a high sensitivity, high specificity, and high positive predictive value. This allows end } \\
\text { users to have confidence in the accuracy of the data }\end{array}$ \\
\hline Utility & The system should be practical, affordable, and increase knowledge about the problem \\
\hline Sustainability & $\begin{array}{l}\text { The system should be easy to maintain and update, with adequate human and financial } \\
\text { resources allocated to assuring its ongoing operation }\end{array}$ \\
\hline Timeliness & The system should generate up-to-date information with minimal delays \\
\hline Responsiveness & $\begin{array}{l}\text { The system should be supported by infrastructure and resources to take action based on } \\
\text { the data }\end{array}$ \\
\hline
\end{tabular}

Butchart et al., (2006 p.29) adapted from Woodruff et al. (2009) 
sources to offer a more reliable picture of the extent of child maltreatment (Gilbert et al., 2012; Leeb \& Fluke, 2015; Merrick \& Latzman, 2014). Ireland could contemplate any of the aforementioned surveillance strategies as a blueprint for a national system. In a world without budgetary constraints, Ireland might look to models used in the USA (NIS) or the Netherlands (NPM); both have compelling datasets due to the inclusion of children known to services within and beyond child protection and the NPM incorporates adolescent self-report surveys (Euser et al., 2013). Where sentinel or self-report studies are not immediately viable, Jud and colleagues (Jud et al, 2015) suggest that beginning with a "first wave of a professional survey" is most constructive. Alternatively, Ireland could consider using administrative data from Tusla to analyze how the service responds to reported child maltreatment. This would involve lateral thinking to widen the scope of data that is currently collected (ChildONEurope Secretariat, 2009; Jud et al., 2015).

It is our hope that the development of a surveillance programme will progress, as doing so will address the significant gaps in the evidence base that continue to impact the ability of service providers and policymakers in many sectors to deliver lasting and impactful services. It will facilitate the benchmarking of prevalence of abuse and examination of the effectiveness of interventions against those in other countries. Of greatest significance, making good on this commitment will assist government in fulfilling its obligation to facilitate the enjoyment of the universal and constitutional rights of Irelands' children and families.

Funding Open Access funding provided by the IReL Consortium. Donna O'Leary received a funding award to undertake a $\mathrm{PhD}$ : this paper was partly funded by the Irish Research Council (Grant Number EBPPG/2014/23).

\section{Declarations}

Conflict of Interest The authors declare no competing interests.

Open Access This article is licensed under a Creative Commons Attribution 4.0 International License, which permits use, sharing, adaptation, distribution and reproduction in any medium or format, as long as you give appropriate credit to the original author(s) and the source, provide a link to the Creative Commons licence, and indicate if changes were made. The images or other third party material in this article are included in the article's Creative Commons licence, unless indicated otherwise in a credit line to the material. If material is not included in the article's Creative Commons licence and your intended use is not permitted by statutory regulation or exceeds the permitted use, you will need to obtain permission directly from the copyright holder. To view a copy of this licence, visit http://creativecommons.org/licen ses/by/4.0/.

\section{References}

AIHW. (2021). Child protection data. https://www.aihw.gov.au/reports-data/health-welfare-services/ child-protection/data.

AlEissa, M. A., Fluke, J. D., Gerbaka, B., Goldbeck, L., Gray, J., Hunter, N., et al. (2009). A commentary on national child maltreatment surveillance systems: Examples of progress. Child Abuse \& Neglect, 33(11), 809-814. https://doi.org/10.1016/j.chiabu.2009.08.004 
Anda, R. F., Felitti, V. J., Bremner, J. D., Walker, J. D., Whitfield, C., Perry, B. D., et al. (2006). The enduring effects of abuse and related adverse experiences in childhood. European Archives of Psychiatry and Clinical Neuroscience, 256(3), 174-186.

Axford, N., \& Berry, V. (2018). Perfect bedfellows: Why early intervention can play a critical role in protecting children-A response to Featherstone et al.(2014) 'A marriage made in hell: Child protection meets early intervention.' British Journal of Social Work, 48(1), 254-273.

Brownell, M. D., \& Jutte, D. P. (2013). Administrative data linkage as a tool for child maltreatment research. Child Abuse \& Neglect, 37(2-3), 120-124. https://doi.org/10.1016/j.chiabu.2012.09.013

Buckley, H., \& Burns, K. (2015). Child welfare and protection in Ireland: Déjà vu all over again. In Social work in Ireland: Continuities and changes. Palgrave Macmillan.

Buckley, H., \& O'Nolan, C. (2013). An examination of recommendations from inquiries into events in families and their interactions with State services, and their impact on policy and practice. DCYA. Dublin: Government Publications.

Buckley, H., \& Whelan, S. (2018). Report on the demographic profile of children at ongoing risk of child abuse. Department of Children and Youth Affairs.

Buckley, H., Carr, N., \& Whelan, S. (2011). 'Like walking on eggshells': Service user views and expectations of the child protection system: Views and expectations of the child protection system. Child \& Family Social Work, 16(1), 101-110. https://doi.org/10.1111/j.1365-2206.2010.00718.x

Burns, K., \& MacCarthy, J. (2012). An impossible task? Implementing the recommendations of child abuse inquiry reports in a context of high workloads in child protection and welfare. Irish Journal of Applied Social Studies, 12. https://doi.org/10.21427/D7172P.

Burns, K., \& McGregor, C. (2019). Child protection and welfare systems in Ireland: Continuities and discontinuities of the present. In L. Merkel-Holguin, J. D. Fluke, \& R. D. Krugman (Eds.), National Systems of Child Protection (Vol. 8, pp. 115-138). Springer International Publishing.

Butchart, A., \& Mikton, C. (2014). Global status report on violence prevention, 2014. World Health Organization.

Bywaters, P., Brady, G., Sparks, T., Bos, E., Bunting, L., Daniel, B., ... Scourfield, J. (2015). Exploring inequities in child welfare and child protection services: Explaining the 'inverse intervention law.' Children and Youth Services Review, 57, 98-105.

CAN-MDS (2021). CAN Via MDS. CAN-MDS II OUTPUTS. http://can-viamds.eu/.

Child Care Act. (1991). Irish statute book.

ChildONEurope (2009). Guidelines on data collection and monitoring systems on child abuse. ChildOnEurope. Florence.

Christ, S. L., \& Schwab-Reese, L. M. (2020). Shedding the constraints of formal systems in research on child maltreatment through high-quality measurement and broad population surveys. International Journal on Child Maltreatment: Research, Policy and Practice, 1-19.

CP MERG. (2012), Ethical principles, dilemmas and risks in collecting data on violence against children: A review of available literature, Statistics and Monitoring Section/Division of Policy and Strategy, UNICEF, New York

CRC, U. (2011). General Comment No. 13 (2011) The right of the child to freedom from all forms of violence.

CSO. (2020). Recorded crime - Statistics under reservation. https://www.cso.ie/en/statistics/crimeandju stice/. Accessed 14 January 2021.

Data Protection Commission, Ireland. (2019). Guidance note: Guidance on anonymisation and pseudonymisation. DPC.

Department of Health and Children. (1999). Children First: National guidelines for the protection and welfare of children (1st ed.). Government Publications, Dublin.

DCYA. (2011). Children First: National guidance for the protection and welfare of children. Government Publications, Dublin.

DCYA. (2014). Better outcomes, brighter futures: The national policy framework for children and young people 2014-2020. Government Publications.

DCYA. (2015). National strategy on children and young people's participation in decision-making, 2015-2020. DCYA. Dublin: Government Publications.

DCYA. (2016). State of the Nation's Children: Key findings. Government Publications, Dublin.

DCYA. (2017). Children First: National guidance for the protection and welfare of children. Government Publications, Dublin.

DHHS (2020). Child Maltreatment 2018. US Administration for Children and Families, Administration on Children, Youth and Families, Children's Bureau. 
Drake, B., \& Jonson-Reid, M. (1999). Some thoughts on the increasing use of administrative data in child maltreatment. Child Maltreatment, 4(4), 308-315.

Department of Education. (2020). Characteristics of children in need: 2019 to 2020. Characteristics of Children in need statistics and data. https://www.gov.uk/government/statistics/characteristics-ofchildren-in-need-2019-to-2020. Accessed February 20th, 2021.

EC. (2018). The rights, equality and citizenship programme funding \& tender opportunties. https://ec. europa.eu/info/funding-tenders/opportunities/portal/screen/programmes/rec\#c,calls=hasForthco mingTopics/t/true/0/1/0/default-group\&hasOpenTopics/t/true/1/1/0/default-group\&allClosedT opics/t/true/0/1/0/default-group\&+PublicationDateLong/asc. Accessed 18th March 2021.

Elliott, I. (2020). Historical sexual abuse in scouting: A learning review. Independent Safeguarding Consultant.

EP, \& CEU. (2016). Regulation (EU) 2016/679 of the European Parliament and of the Council of 27 April 2016 on the protection of natural persons with regard to the processing of personal data and on the free movement of such data, and repealing Directive 95/46/EC (General Data Protection Regulation). In E. P. a. C. o. t. E. Union (Ed.).

Euser, S., Alink, L. R., Pannebakker, F., Vogels, T., Bakermans-Kranenburg, M. J., \& Van IJzendoorn, M. H. (2013). The prevalence of child maltreatment in the Netherlands across a 5-year period. Child Abuse \& Neglect, 37(10), 841-851.

Fallon, B., Trocmé, N., Fluke, J., MacLaurin, B., Tonmyr, L., \& Yuan, Y.-Y. (2010). Methodological challenges in measuring child maltreatment. Child Abuse \& Neglect, 34(1), 70-79.

Fallon, B., Filippelli, J., Black, T., Trocmé, N., \& Esposito, T. (2017). How can data drive policy and practice in child welfare? Making the link in Canada. International Journal of Environmental Research and Public Health, 14(10), 1223.

Fluke, J. D., Tonmyr, L., Gray, J., Bettencourt Rodrigues, L., Bolter, F., Cash, S., et al. (2020). Child maltreatment data: A summary of progress, prospects and challenges. Child Abuse \& Neglect, 104650, https://doi.org/10.1016/j.chiabu.2020.104650

Furey, E., \& Canavan, J. (2019). A review on the availability and comparability of statistics on child protection and welfare, including children in care, collated by Tusla: Child and Family Agency with statistics published in other jurisdictions.

Gibbons, N., Lunny, L., Harrison, P., \& O'Neill, G. (2010). Roscommon child care case: Report of the inquiry team to the health service executive. Health Services Executive.

Gilbert, R., Widom, C. S., Browne, K., Fergusson, D., Webb, E., \& Janson, S. (2009). Burden and consequences of child maltreatment in high-income countries. The Lancet, 373(9657), 68-81. https:// doi.org/10.1016/S0140-6736(08)61706-7

Gilbert, R., Fluke, J., O’Donnell, M., Gonzalez-Izquierdo, A., Brownell, M., Gulliver, P., et al. (2012). Child maltreatment: Variation in trends and policies in six developed countries. Lancet, 379(9817), 758-772. https://doi.org/10.1016/S0140-6736(11)61087-8

Graham, A., Powell, M., Taylor, N., Anderson, D. \& Fitzgerald, R. (2013). Ethical research involving children. UNICEF Office of Research - Innocenti.

Gray, M., \& Schubert, L. (2019). Critiques of a public health model in child maltreatment. In Re-Visioning Public Health Approaches for Protecting Children (Vol. 9). Springer International Publishing.

Horwath, J. (2005). Identifying and assessing cases of child neglect: Learning from the Irish experience. Child \& Family Social Work, 10(2), 99-110. https://doi.org/10.1111/j.1365-2206.2005.00356.x

Hurren, E., Stewart, A., \& Dennison, S. (2017). New methods to address old challenges: The use of administrative data for longitudinal replication studies of child maltreatment. International Journal of Environmental Research and Public Health, 14(9), 1066. https://doi.org/10.3390/ijerph1409 1066

HSE. (2009). HSE child welfare and protection social work departments business processes. Report of the NCCIS Business Process Standardisation Project (Vol. 0.9 ). HSE, Child and Family Social Services.

Jud, A., Fegert, J. M., \& Finkelhor, D. (2016). On the incidence and prevalence of child maltreatment: A research agenda. Child and Adolescent Psychiatry and Mental Health, 10(1), 17. https://doi.org/10. $1186 / \mathrm{s} 13034-016-0105-8$

Jud, A. (2018). Current research on child maltreatment epidemiology. Child and Adolescent Psychiatry and Mental Health, 12(1), 21,-s13034-13018-10228-13031. https://doi.org/10.1186/ s13034-018-0228-1.

Jud, A., Fluke, J., Alink, L. R. A., Allan, K., Fallon, B., Kindler, H., et al. (2013). On the nature and scope of reported child maltreatment in high-income countries: Opportunities for improving the 
evidence base. Paediatrics and International Child Health, 33(4), 207-215. https://doi.org/10. 1179/2046905513Y.0000000092

Jud, A., Jones, L., Mikton, C., Eds. (2015). Toolkit on mapping legal, health and social services responses to child maltreatment. WHO, Geneva.

Klevens, J., \& Alexander, S. (2019). Essentials for childhood: Planting the seeds for a public health approach to preventing child maltreatment. International Journal on Child Maltreatment: Research, Policy and Practice, 1(2), 121-132.

Krug, E. G., Dahlberg, L. L., Mercy, J. A., Zwi, A. B., \& Lozano, R. (Eds.). (2002). World report on violence and health. World Health Organization.

Leeb, R. T., \& Fluke, J. D. (2015). Child maltreatment surveillance: Enumeration, monitoring, evaluation and insight. Health Promotion and Chronic Disease Prevention in Canada, 35(8), 3.

Lonne, B., Russ, E., Harrison, C., Morley, L., Harries, M., Robertson, S., et al. (2020). The "Front Door" to Child Protection-Issues and Innovations. International Journal on Child Maltreatment: Research, Policy and Practice. https://doi.org/10.1007/s42448-020-00051-9.

Mathews, B., Pacella, R., Dunne, M. P., Simunovic, M., \& Marston, C. (2020). Improving measurement of child abuse and neglect: A systematic review and analysis of national prevalence studies. PLoS ONE, 15(1), e0227884. https://doi.org/10.1371/journal.pone.0227884

Merrick, M., \& Latzman, N. (2014). Child maltreatment a public health overview and prevention considerations. OJIN: The Online Journal of Issues in Nursing, 19(1).

McGee, H., Garavan, R., de Barra, M., Byrne, J., \& Conroy, R. (2002). The SAVI report: Sexual abuse and violence in Ireland.

McGregor, C. (2014). Why is history important at moments of transition? The case of 'transformation' of Irish child welfare via the new Child and Family Agency. European Journal of Social Work, 17(5), 771-783. https://doi.org/10.1080/13691457.2014.927833

McGuinness, C. (1993). Report of the Kilkenny incest investigation. The Stationery Office.

Meinck, F., Steinert, J.I., Sethi, D., Gilbert, R., Bellis, M.A., Mikton, C., Alink, L. and Baban, A., (2016). Measuring and monitoring national prevalence of child maltreatment: A practical handbook. World Health Organization Regional Office for Europe.

Nikolaidis, G., Petroulaki, K., Zarokosta, F., Tsirigoti, A., Hazizaj, A., Cenko, E., et al. (2018). Lifetime and past-year prevalence of children's exposure to violence in 9 Balkan countries: the BECAN study. Child and Adolescent Psychiatry and Mental Health, 12(1), 1-15.

Nixon, E. (2019). Children's lives in Ireland-Insights from the growing up in Ireland study. Paper presented at the The Challenges of Success Addressing Population Growth in Ireland.

NSPCC. (2013-2019). How safe are our children? 2020. https://learning.nspcc.org.uk/research-resou rces/how-safe-are-ourchildren2020

Ntinapogias, A., Gray, J., Durning, P., \& Nikolaidis, G. (2015). CAN-MDS surveillance system policy and procedures manual. DAPHNE III Programme "Coordinated Response to Child Abuse \& Neglect (CAN) via Minimum Data Set (MDS)”. Institute of Child Health, Department of Mental Health and Social Welfare - GREECE.

O'Leary, D., O'Sullivan, K., Fitzgerald, T., \& Christie, A. (2015). Poverty and decisions to place in care (residential and foster care): Mapping placements in care using street level deprivation indices. Paper presented at the ECSWR 5th European Conference for Social Work Research "Re-visioning social work with individuals, collectives and commuities: social work research", Ljubljana, 22-24 April 2015.

O'Mahony, C. (2020). Annual report of the special rapporteur on child protection. Department of Children and Youth Affairs.

ONS. (2021). Exploring the feasibility of a survey measuring child abuse in the UK. Office for National Statistics.

Oranga Tamariki_-Ministry for Children (2021). Child protection and youth justice statistics 20172020. Oranga Tamariki-Ministry for Children. Accessed 30th March 2021.

Parton, N. (2006). Safeguarding childhood: Early intervention and surveillance in a late modern society. Red Globe Press.

Parton, N. (2019). Changing and competing conceptions of risk and their implicatioins for public health approaches to child protection. In Re-Visioning Public Health Approaches for Protecting Children (Vol. 9). Springer International Publishing.

Perry, I. (2009). Violence: A public health perspective. Global Crime, 10(4), 368-395. 
Power, J. (2020). 'Sex offenders dominated leadership' of scouting body for decades, report finds. https:// www.irishtimes.com/news/social-affairs/sex-offenders-dominated-leadership-of-scouting-bodyfor-decades-report-finds-1.4253310.

Reading, R., Bissell, S., Goldhagen, J., Harwin, J., Masson, J., Moynihan, S., et al. (2009). Promotion of children's rights and prevention of child maltreatment. The Lancet, 373(9660), 332-343. https:// doi.org/10.1016/S0140-6736(08)61709-2

Runyan, D., Brandspigel, S., Zolotor, A., \& Dunne, M. (2015). Manual for administration: The ISPCAN child abuse screening tool (ICAST). International Society for the Prevention of Child Abuse and Neglect.

Ryan, S. (2009). The report of the commission to inquire into child abuse. Dublin.

Scott, D., \& Faulkner, A. (2019). The role, importance and challenges of data for a public health model. In Re-Visioning Public Health Approaches for Protecting Children (pp. 253-267). Springer.

Scott, D., Lonne, B., \& Higgins, D. (2016). Public health models for preventing child maltreatment: Applications from the field of injury prevention. Trauma, Violence, \& Abuse, 17(4), 408-419.

Sedlak, A.J., Mettenburg, J., Basena, M., Petta, I., McPherson, K., Greene, A., \& Li, S. (2010). Fourth national incidence study of child abuse and neglect (NIS-4): Report to congress, executive summary. U.S. Department of Health and Human Services, Administration for Children and Families.

Sethi, D., Bellis, M., Hughes, K., Gilbert, R., Mitis, F., \& Galea, G. (Eds.). (2013). European report on preventing child maltreatment. WHO Regional Office for Europe.

Sethi, D., Yon, Y., Parekh, N., Anderson, T., Huber, J., Rakovac, I., et al. (Eds.). (2018). European status report on preventing child maltreatment. WHO Regional Office for Europe.

Shannon, D. G. (2017). Audit of the exercise by An Garda Siochana of the provision of Section 12 of the Child Care Act 1991. An Garda Siochana.

Shore, C., \& Powell, F. (2020). The social construction of child abuse in Ireland: Public discourse, policy challenges and practice failures. In Biesel, K., Masson, J., Parton, N., \& Poso, T (Eds.). (2020). Errors and Mistakes in Child Protection: International discourses, approaches and strategies. (pp. 55-73). Policy Press.

Sidebotham, P. (2001). An ecological approach to child abuse: A creative use of scientific models in research and practice. Child Abuse Review, 10(2), 97-112. https://doi.org/10.1002/car.643

SI.No.470/2017 (2017). S.I. No. 470/2017-Children First Act 2015 (Commencement) Order 2017. In G. Ireland (Ed.). Dublin.

Thorpe, D. (1997). Review essay: Regulating late modern childrearing in Ireland. The Economic and Social Review, 28(1), 63-84.

Tonmyr, L., \& Martin, W. K. (2014). How has child maltreatment surveillance data been used in Canada? Health Research Policy and Systems, 12(1), 1-9.

Trocmé, N., MacLaurin, B., Fallon, B., Daciuk, J., Billingsley, D., Tourigny, M., et al. (2001). Canadian incidence study of reported child abuse and neglect: Final report: (614172012-001) . American Psychological Association.

Trocmé, N., Fallon, B., MacLaurin, B., Sinha, V., Black, T., Fast, E., et al. (2010). Canadian incidence study of reported child abuse and neglect: 2008 major findings. Public Health Agency of Canada.

Trocmé, N., Roy, C., \& Esposito, T. (2016a). Building research capacity in child welfare in Canada. Child and Adolescent Psychiatry and Mental Health, 10(1), 16. https://doi.org/10.1186/ s13034-016-0103-X

Trocmé, N., Akesson, B., \& Jud, A. (2016b). Responding to child maltreatment: A framework for mapping child protection agencies. Child Indicators Research, 9(4), 1029-1041. https://doi.org/10. 1007/s12187-015-9362-y

Trocmé, N., Esposito, T., Fallon, B., Chabot, M., \& Delaye, A. (2019). Building research capacity in child welfare in Canada: Advantages and challenges in working with administrative data. In $R e$ Visioning Public Health Approaches for Protecting Children (Vol. 9, pp. 433-454). Springer International Publishing.

Tusla (2014a). Assessment guidance framework. In D. o. P. Strategy (Ed.), (June 2015 ed., Vol. V5, pp. 55). Tusla CFA.

Tusla (2014b). Threshold of need guidance for practitioners in Tusla social work services. In P. a. Strategy (Ed.), (pp. 15). Tusla CFA.

Tusla. (2015). National audit of the standard business processes for child protection and welfare social work services: Intake and initial assessment. (Vol. V 1.9). Tusla: Quality Assurance Directorate.

Tusla. (2020a). About Us Tusla-Child and Family Agency. About Us. Welcome to the Child and Family Agency Website. https://www.tusla.ie/about/. 
Tusla (2020b) Tusla statement on child abuse substantiation procedure CASP, 4th February 2020 available at https://www.tusla.ie/news/tusla-statement-on-child-abuse-substantiation-procedure-casp/.

U.S. Department of Health \& Human Services, Administration for Children and Families, Administration on Children, Youth and Families, Children's Bureau. (2021). Child maltreatment 2019. Available from https://www.acf.hhs.gov/cb/research-data-technology/ statistics-research/child-maltreatment.

UNCRC. (2011). General Comment No13, (2011). The right of the child to freedom from all forms of violence. United Nations Committee on the Rights of the Child.

UN Committee on the Rights of the Child (CRC) General Comment No. 13. (2011). The right of the child to freedom from all forms of violence CRC/C/GC/13 (2011b). UN CRC. https://www.refwo rld.org/docid/4e6da4922.html. Accessed 6 December 2018.

UNICEF. (2018). INSPIRE indicator guidance and results framework-ending violence against children: How to define and measure change. UNICEF.

UNICEF. (2020). United Nations children's fund, research on violence against children during the COVID-19 pandemic: Guidance to inform ethical data collection and evidence generation. UNICEF.

Vaithianathan, R., Putnam-Hornstein, E., Jiang, N., Nand, P., \& Maloney, T. (2017). Developing predictive models to support child maltreatment hotline screening decisions: Allegheny county methodology and implementation (p. 60). Centre for Social data analytics, AUT University, New Zealand.

van Berkel, S. R., Prevoo, M. J. L., Linting, M., Pannebakker, F. D., \& Alink, L. R. A. (2020). Prevalence of child maltreatment in the Netherlands: An update and cross-time comparison. Child Abuse \& Neglect, 103, 104439. https://doi.org/10.1016/j.chiabu.2020.104439.

WHO. (1999). Report of the consultation on child abuse prevention, 29-31 March 1999, WHO, Geneva. World Health Organization.

WHO. (2006). Preventing child maltreatment: a guide to taking action and generating evidence. WHO, Geneva

WHO. (2014). Investing in children: The European child maltreatment prevention action plan 20152020. WHO Regional Office for Europe.

WHO. (2016). INSPIRE: Seven strategies for ending violence against children. World Health Organization.

WHO (2017). WHO guidelines on ethical issues in public health surveillance. WHO, Geneva.

WHO. (2018). INSPIRE handbook: Action for implementing the seven strategies for ending violence against children. https://www.who.int/publications/i/item/inspire-handbook-action-for-implementi ng-the-seven-strategies-for-ending-violence-against-children.

Wilkinson, R. G., \& Pickett, K. E. (2009). Income inequality and social dysfunction. Annual Review of Sociology, 35, 493-511.

Woodruff, B. W., Bornemisza, O., Checchi, F., \& Sondorp, E. (2009). The use of epidemiological tools in conflict-affected populations: open-access educational resources for policy-makers. http://conflict. 1shtm.ac.uk/page_02.htm.

Woollard, M. (2014). Administrative data: Problems and benefits. A perspective from the United Kingdom. In A. Dusa, D. Nelle, G. Stock, \& G. G. Wagner (Eds.), Facing the future: European research infrastructures for the humanities and social sciences, Berlin (Vol. 1st)

Publisher's Note Springer Nature remains neutral with regard to jurisdictional claims in published maps and institutional affiliations. 